\title{
Filling the Tank on Fridays May Be a Bad Idea for St. Louisans
}

\author{
YiLi Chien, Senior Economist \\ Paul Morris, Research Associate
}

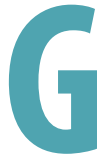
as prices in many midwestern cities and St. Louis in particular follow a regular weekly pattern. ${ }^{1}$ What is driving the phenomenon?

The figure plots average daily prices of regular gasoline in St. Louis, Denver, and the nation over the past 6 months. Unsurprisingly, average gas prices in St. Louis and Denver have followed the national trend-generally declining with crude oil prices until mid-February. The average for St. Louis exhibits an additional striking feature-a large price increase followed by smaller price cuts followed by a large price increase. This cyclical pattern is found in many midwestern cities but typically not in cities outside the Midwest, such as Denver.

Zimmerman, Yun, and Taylor (2013) find that cyclical gas pricing occurs primarily in the Midwest and began in 2000 and spread to St. Louis by 2001. The price increases in St. Louis can be significant, ranging from 10 to 25 cents or more per gallon-a more than 10 percent overnight jump. Gallagher (2015) found that the cycle in St. Louis is hard to predict and does not occur on a regular schedule. Our examination, however, finds a much more definitive pattern: The average gas price almost always jumps in the second half of the week and then continues to decrease until the next surge. The shading in the figure represents Thursdays, Fridays, and Saturdays and highlights this pattern.

Cyclical gas pricing is consistent with what are known as Edgeworth cycles: Gas stations undercut each other on price to gain business. When retail gas prices approach the wholesale cost of gasoline, a more-dominant firm will increase its prices. Other gas stations follow suit, thereby resetting the cycle.

Many studies have focused on the relationship between the market structure of gasoline retailers and Edgeworth cycles. The degree of concentration in a given marketthat is, the number of gas station owners and their relative market shares-seems to determine whether gas pricing is cyclical. High concentration indicates a small number of relatively dominant firms, while low concentration indicates

\section{Average Daily Prices of Regular Gasoline}

Price (\$/Gallon)

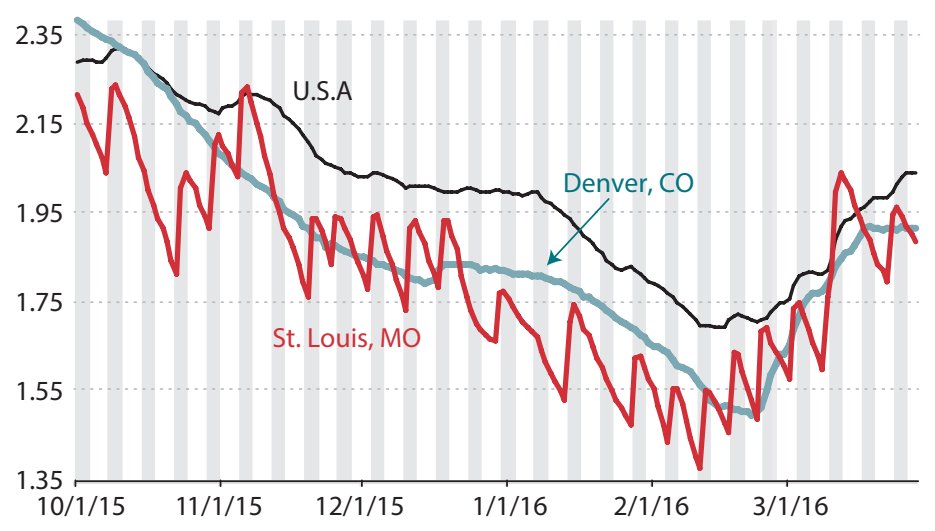

SOURCE: GasBuddy.com. Last observation 3/28/2016.

many firms and greater competition. Doyle, Muehlegger, and Samphantharak (2010) show that markets with considerably high or low market concentration are less likely to support cyclical gas pricing. Dominant firms in highly concentrated markets have little incentive to decrease prices, and firms in competitive markets lack the ability to reset the cycle by increasing prices. Markets with intermediate concentration have been shown more likely to support cyclical gas pricing, which seems to be the case in the Midwest.

Midwestern cities, such as St. Louis, appear to have an intermediate concentration of gasoline retailers. Lewis (2012) finds that two specific independent midwestern retail chains ${ }^{2}$ contribute to cyclical gas pricing in many of the cities. These firms have enough market influence to act as price leaders and often are the first to increase prices from cycle to cycle. He finds that cyclical pricing occurs in nearly every city where these chains have a significant presence in the retail gasoline market. We suspect, however, that these firms do not have enough influence to set a high 
steady market price, but rather can only start a cycle that keeps prices above cost temporarily. One of the independent chains has a substantial presence in St. Louis, making it a likely contributor to the sawtooth pattern in St. Louis gas prices.

\section{Gas prices in St. Louis can jump 10 percent overnight.}

It is not entirely clear why cyclical pricing in St. Louis follows a roughly weekly timetable with peaks on Thursdays, Fridays, and Saturdays. It is possible that demand for gasoline is higher during the weekend, and gas stations raise prices to take advantage of this effect. Overall, customers may not notice a pricing pattern and, even if they did, some may not find it significant enough to change behavior, thus creating an incentive for gas stations to raise prices on these days relative to others.

Cyclical pricing may not be bad for consumers, however. Zimmerman, Yun, and Taylor (2013) show that once cyclical pricing started in a metropolitan statistical area, average gas prices tended to decline in that area compared with areas with no cyclical pricing, controlling for other factors. This finding suggests that cyclical pricing is a form of competition. In addition, consumers can save if they identify the cycle floor and buy then. Given the regularity of the cycle in St. Louis over the past six months, residents can likely save a few bucks if they fill up earlier in the week.

\section{Notes}

1 For an overview of the literature on gasoline prices, see Federal Trade Commission Bureau of Economics (2011).

2 Large independent retail chains can control the prices of many stations at once. Branded stations such as BP and Shell are often owned or operated under contractual agreement by businesses that control up to a handful of stations.

\section{References}

Doyle, Joseph; Muehlegger, Erich and Samphantharak, Krislert. "Edgeworth Cycles Revisited." Energy Economics, May 2010, 32(3), pp. 651-60.

Federal Trade Commission Bureau of Economics. "Gasoline Price Changes and the Petroleum Industry: An Update." FTC Staff Study, September 2011.

Gallagher, Jim. "Can You Time the Gasoline Market?" St. Louis Post-Dispatch. November 7, 2015.

Lewis, Matthew. S. "Price Leadership and Coordination in Retail Gasoline Markets with Price Cycles." International Journal of Industrial Organization, July 2012, 30(4), pp. 342-51.

Zimmerman, Paul R.; Yun, John M. and Taylor, Christopher T. "Edgeworth Price Cycles in Gasoline: Evidence from the United States." Review of Industrial Organization, May 2013, 42(3), pp. 297-320. 